\title{
Streamflow response to climate change in the Greater Horn of Africa
}

\author{
Feyera A. Hirpa ${ }^{1}$ (D) $\cdot$ Lorenzo Alfieri $^{2} \cdot$ Thomas Lees $^{1} \cdot$ Jian Peng ${ }^{1} \cdot$ Ellen Dyer $^{1}$. \\ Simon J. Dadson ${ }^{1,3}$
}

Received: 18 February 2019 / Accepted: 27 August 2019 / Published online: 12 September 2019

(C) The Author(s) 2019

\begin{abstract}
The Greater Horn of Africa region increasingly experiences high risk of water scarcity. A combination of frequent droughts, rapid population growth and rising urbanisation has reduced streamflow and intensified water abstraction, causing water and food shortages. Estimates of future streamflow changes in the region have so far been highly uncertain and evaluations using ground-based measurements are still limited. Here, future streamflow changes are estimated using a distributed hydrological model forced with an ensemble of high-resolution climate simulations produced using the European community Earth-System Model v3.1. The simulated streamflow is evaluated using observed data from 29 stations from river basins across different climate zones in the region. Evaluation results show large sub-regional variations in the performance of simulated streamflow. The sign and magnitude of future streamflow changes vary between climate simulations and river basins, highlighting the uncertainties in the hydrologic projections. Overall, the streamflow projections indicate large (seasonal, long-term mean and extreme) streamflow decreases for all major rivers in Ethiopia and increases in the equatorial parts of the region at the end of the century. The ensemble mean shows a 10 to $25 \%$ decrease in the long-term mean flow in Ethiopia and a $10 \%$ increase in the equatorial part of the region in 2080s. Similarly, there is a substantial change in high flows in 2080 s, with up to $-50 \%$ reduction in the northern and $50 \%$ increase in the equatorial parts of the region. These findings are critical because the rivers provide water supply to a rapidly changing socio-economy of the region.
\end{abstract}

\section{Introduction}

Water scarcity is one of the pressing global challenges, with wide-ranging societal and environmental impacts. It affects food security, energy production, human health and the

Electronic supplementary material The online version of this article (https://doi.org/10.1007/s10584-01902547-x) contains supplementary material, which is available to authorized users.

Feyera A. Hirpa

agahirpa@gmail.com

Extended author information available on the last page of the article 
ecosystem and can potentially lead to conflicts and mass migration (Kumssa et al. 2009; Mekonnen and Hoekstra 2016; Hohenthal and Minoia 2017). Global water scarcity is driven by a lack of sufficient water to meet demands (physical water scarcity), poor water resources development (economic water scarcity) or a combination thereof (WWAP (World Water Assessment Programme) 2012).

The Greater Horn of Africa (GHA) region experiences a compound effect of both physical and economic water scarcity, often causing extreme water and food shortages (IWMI 2007; Nicholson 2014; Awange et al. 2016; FEWS NET 2017). Rapid population growth and highly variable climate conditions may increase future risks of water scarcity in the region. Hydrological impact studies, which are critical for water resources planning, have been hindered by the coarse global circulation model (GCM) resolutions not capable of capturing the small-scale rainfall patterns, large uncertainty in both GCM and regional climate models (RCM) rainfall projections and the lack of model verification using measured streamflow in the region (Otieno and Anyah 2013; Endris et al. 2016; Shiferaw et al. 2018).

Here, we estimate the future streamflow changes from long-term streamflow time series produced using a distributed hydrological model forced with an ensemble of high-resolution climate simulations, which can potentially overcome some of the problems faced by the coarse-resolution GCM previously used in hydrological impact studies. The climate simulations were produced using a newly improved atmosphereonly climate model EC-EARTH3-HR forced with a set of sea surface temperature (SST) and sea ice concentration (SIC) values from different climate runs. Since rainfall in the GHA region is sensitive to equatorial SST, the use of multiple SST forcings from different climate models can produce a wide range of streamflow realisations. This experimental design has recently been used for assessment of future changes in global extreme (flood and drought) conditions (Alfieri et al. 2017; Naumann et al. 2018). However, the current study is the first to perform a regional hydrological assessment and evaluation using streamflow measurements.

In addition to evaluating the present-time streamflow simulations using in situ data across climatic zones, we quantify the future streamflow changes in response to global climate change and explore the sensitivity of the regional streamflow to SST by using the single climatehydrology model driven by multiple SST, described above. The results of our work will have important implications for climate adaptation planning to sustain water, food and energy supply to meet the rapidly growing demand in the region.

\section{Study region, model and data}

\subsection{The Greater Horn of Africa}

The GHA region (Fig. 1) consists of 11 countries with a combined population of 360 million (one third of Sub-Saharan Africa) and projected to reach 1.2 billion by the end of the twentyfirst century (United Nations 2017a). Urbanisation is rapidly increasing with a projected average annual growth rate of 3-4\% during 2020-2050 across the countries in the region (United Nations 2018). The region's food supply primarily relies on rainfed agriculture, which makes it highly vulnerable to climate variability (Barrios et al. 2008). Between 2000 and 2017, $1.8 \%$ of the GHA population have migrated to other countries although it is not clear how much of this can be attributed to climate disasters (United Nations 2017b). 


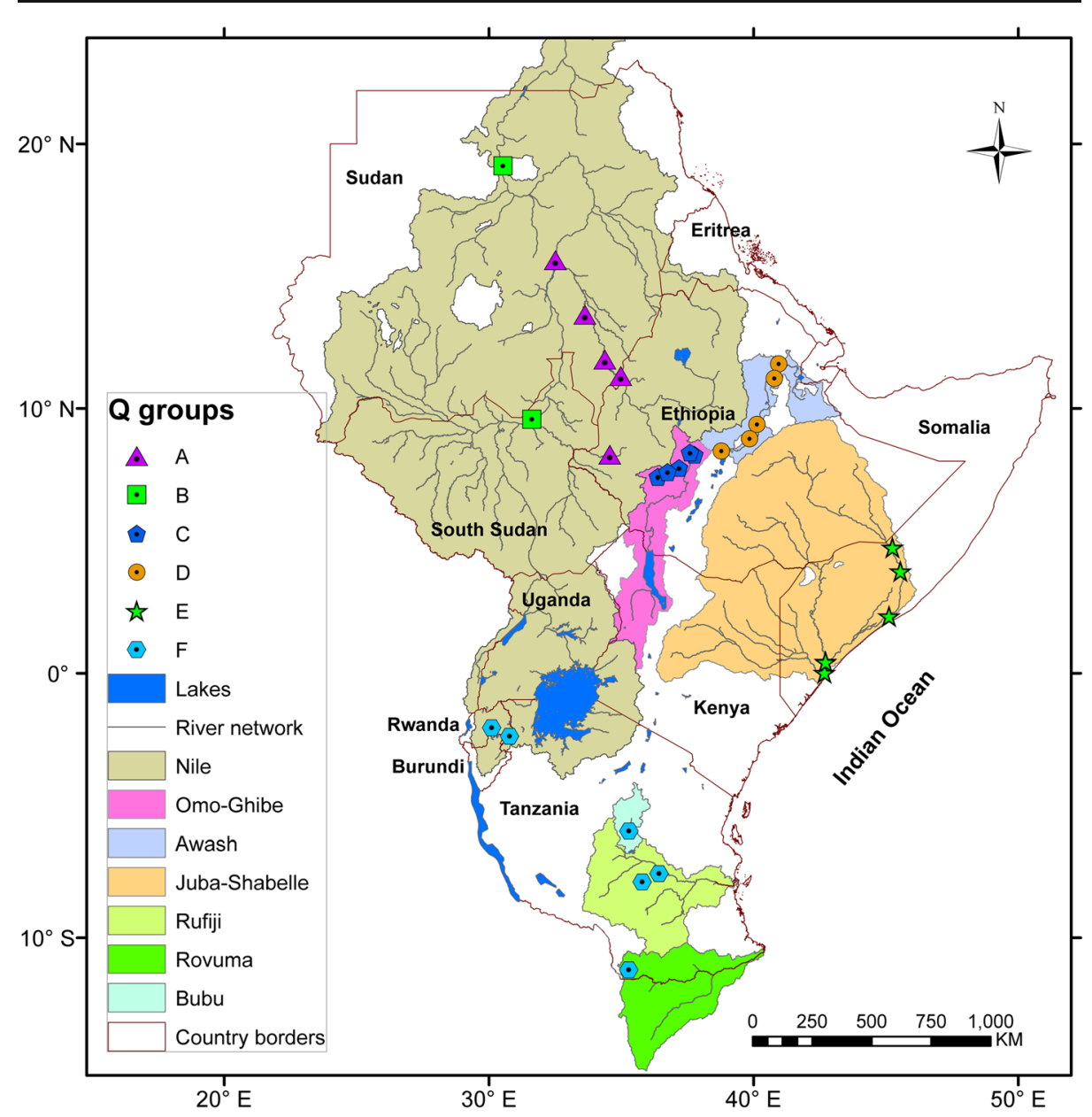

Fig. 1 The Greater Horn of Africa (GHA) region with country borders, river basins and the locations of streamflow data used for evaluation. See Table $\mathrm{S} 1$ for the description of the $Q$ sub-regions

The region's hydroclimate is characterised by high spatio-temporal variability. The equatorial part (south-eastern Ethiopia, Somalia and Kenya) has two rainy seasons: March-May (MAM) and October-December (OND). The northern sub-region (Ethiopian highlands, Sudan and South Sudan) experiences unimodal rainy season during June-September (JJAS), whereas the southern part (e.g., Tanzania) exhibits a unimodal but a longer rainfall season during December-May. The rainfall (and river flow) variability in the region is largely influenced by large-scale drivers of climate variability such as El Niño-Southern Oscillation (ENSO) and Indian Ocean Dipole (IOD) (Black 2005; Ficchì and Stephens 2019). Teleconnection between Ethiopian summer rainfall and equatorial Pacific sea surface temperature and ENSO has been recognised (Diro et al. 2011). The Western Pacific sea surface temperature gradient influences the MAM rainfall (Hoell and Funk 2014; Funk et al. 2015), whereas the OND rains in the equatorial sub-region are linked with IOD, with the positive IOD phase leading to more rainfall (Black 2005; Bhattacharjee and Zaitchik 2015). 


\subsection{Hydrological model}

The LISFLOOD rainfall-runoff model was used for hydrological simulations (Burek et al. 2013). It is a spatially distributed two-soil layer model, with sub-models for simulating different hydrological processes (such as evaporation, transpiration, infiltration, preferential flow, soil moisture redistribution, groundwater flow and flow routing). It first produces surface and subsurface runoff at a grid scale (here at $0.5^{\circ}$ resolution and daily time steps) and routes the flows using its one-dimensional runoff routing scheme with a 4-point implicit finite difference solution of the kinematic wave equation.

Lakes and reservoirs were not activated in the LISFLOOD model used in this study, and the model parameters were not specifically calibrated. Therefore, the hydrologic simulations are subject to potential errors from human-made flow regulations and parameter uncertainty. The topography, river network and land use datasets were obtained from global databases (Bontemps et al. 2011; Wu et al. 2012; Yamazaki et al. 2014). The same spatial datasets and model parameters were used for future streamflow simulations. The LISFLOOD model has been used in numerous other studies including continental and global-scale flood and drought forecasting systems (Hirpa et al. 2018; Thielen et al. 2009).

\subsection{Climate simulations}

An ensemble of high-resolution $\left(0.35^{\circ}\right.$ horizontal resolution and daily time step) climate model output was used to drive the hydrological model. The climate datasets were produced by the Swedish Meteorological and Hydrological Institute (SMHI) using an atmosphere-only setup of the European community Earth-System Model v3.1 (EC-EARTH3-HR, http://www.ec-earth. org). The model was driven by sea surface temperature (SST) and sea ice concentrations (SIC) from six selected CMIP5 runs with RCP8.5 emission scenario (Wyser et al. 2017, Table S1).

The EC-EARTH-HR is an improved version of the previous EC-EARTH2 CMIP5 model and will participate in the upcoming CMIP6 experiment. It has an increased vertical resolution and improved microphysics to better represent tropical precipitation (Wyser et al. 2017). The primary advantages of this setup compared to the commonly used CMIP5 runs are that the higher resolution provides detailed representation of the regional precipitation which could be more suitable for hydrological modelling and the atmosphere-only runs are computationally faster compared to coupled simulations (Demory et al. 2014; Wyser et al. 2017). Another advantage of this experimental design is that the use of only one model for atmosphere modelling allows the assessment of the sensitivity of the GHA climate to global SST.

\subsection{Streamflow data}

We used monthly streamflow data from 29 stations for the evaluation of the hydrological simulations (Fig. 1; Table S2). The streamflow data, obtained from the Global Runoff Data Centre (GRDC, https://www.bafg.de/GRDC/EN/01_GRDC/13_dtbse/database_node.html) and from national hydrological centres, are distributed across different climatic zones and flow seasonality (Table S3). The stations in the Blue Nile, White Nile, Upper Ghibe and Awash river basins have a unimodal flow regime with high flow during the JJAS season. However, flows in the Makalal station in White Nile and below the Hombole station in Awash are regulated by Lake Victoria and the Koka Dam, respectively. Stations in the Juba-Shabelle river basin have a bimodal season with high flows during MAM and OND. Finally, stations in Tanzania and Rwanda have the observed high flow seasons 
during November-May. However, due to the likely flow regulations for the two stations in Rwanda, the observed streamflow may not reflect the bimodal rainfall season (OND and MAM).

\section{Methods}

\subsection{Streamflow evaluation}

We evaluated the streamflow simulations by comparing simulated against observed streamflow during the 1976-2005 period. All simulations have large (positive) systematic bias compared to the measured flows with long-term average ensemble mean having a bias of $+300 \%$ (median of 29 stations). To reduce the bias, we used a multiplying factor estimated as the ratio between the long-term mean observed and modelled flows for each station as follows:

$$
Q_{\mathrm{m} \_\mathrm{bc}}=Q_{\mathrm{m}} \times\left(\frac{Q_{\mathrm{o} \_\mathrm{ltm}}}{Q_{\mathrm{m} \_\mathrm{ltm}}}\right)
$$

Where $Q_{\mathrm{m}}$ is the ensemble mean of modelled monthly flow $\left(\mathrm{m}^{3} / \mathrm{s}\right), Q_{\mathrm{m}_{-}} \mathrm{ltm}$ is the long-term mean $Q_{\mathrm{m}}, Q_{\mathrm{o}_{-} \text {ltm }}$ is the long-term mean observed flow $\left(\mathrm{m}^{3} / \mathrm{s}\right)$ and $Q_{\mathrm{m}_{-} \text {bc }}$ is the bias-corrected monthly flow $\left(\mathrm{m}^{3} / \mathrm{s}\right)$.

We evaluated whether the simulated streamflow accurately captures the observed flow variability and seasonality using linear correlation coefficient, Nash-Sutcliffe efficiency (NSE), Kling-Gupta efficiency (KGE) and bias (Gupta et al. 2009). Accurately projecting the flow variability and the high/low flow seasons is essential for water resources planning, such as dam operations and water allocation.

\subsection{Streamflow projections}

We quantified the relative change in the projected streamflow compared to the baseline (1976-2005). We selected two 30-year time slices in the near future (2030-2059, 2040s) and in the far future (20702099,2080 s). For all simulations, we computed the projected change (as the percent change compared the baseline) in 30-year mean and seasonal streamflow relative to the baseline period. Further, we calculated the changes in high and low flows, which are important for groundwater recharge (Taylor et al. 2013) and sustaining water supply, respectively. We also showed the future changes in the monthly flow variability compared to the baseline period. Furthermore, we quantify the changes in the magnitude of extreme flows using the changes in the Q95 and Q05 flows, which are derived from the flow duration curve (FDC). The FDC for each grid-cell is estimated from the daily streamflow simulations. The Q95 value (low flow) indicates a flow magnitude that is exceeded 95\% of the time, and the Q05 value (high flow) is exceeded only $5 \%$ of the time.

\section{Results}

\subsection{Streamflow evaluation}

Figure 2 shows the correlation between monthly streamflow simulations and observations for all stations across different sub-regions (see Table S2). The correlation values show large 


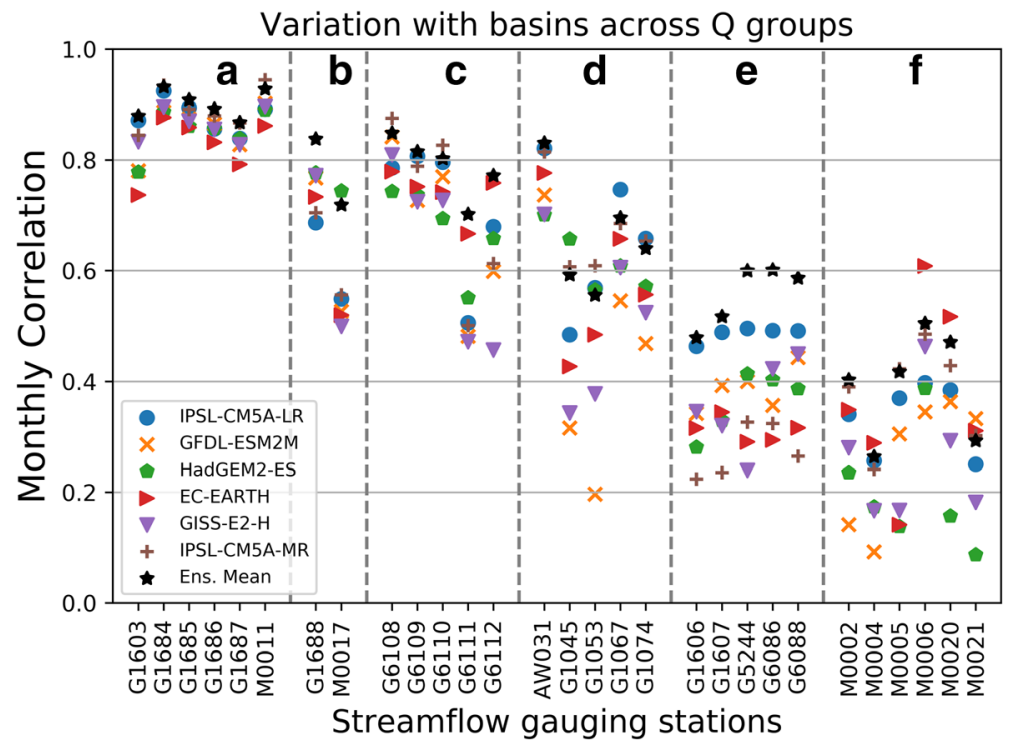

Fig. 2 Monthly correlation between the simulated and observed streamflow. See Table S2 for the classification A-F

variations in the GHA region. Firstly, there is a large variation in the performance of all six streamflow simulations and the mean. The highest correlations $(>0.8)$ with observed streamflow were found in the Blue Nile and Baro basins (A), while the lowest correlations $($ all $<0.5)$ were in basins that are located in the southern part of the GHA region $(\mathrm{F})$. Correlation values for the other stations largely vary between 0.5 and 0.8 . The relatively low correlation for Makalal station (M0017) on the White Nile, South Sudan, is likely due to the flow regulation by Lake Victoria, which has not been included in the hydrological model. Most stations in the Upper Ghibe basin (C) and the Hombole station (AW031) in the Awash basin have a correlation value $>0.7$. The other four stations in Awash basin (D) are influenced by the Koka Dam, showing low correlation due to the dam influence. Finally, stations in the Juba-Shabelle basin (E), which has a bimodal season, have low correlation values $(<0.6)$.

Secondly, the correlation values show large variations between the six streamflow simulations for each station in the region. In general, there is a better agreement between the ensemble simulations for basins with high correlation (e.g., in Blue Nile basin), and less agreement in basins where the correlation with the observed streamflow is low (e.g., JubaShabelle stations). Simulations produced with IPSL-CM5A-LR or IPSL-CM5A-MR forcings outperform the rest for the majority of the stations. In general, the mean of the six streamflow simulations has higher correlation than any individual run, with very few exceptions.

The KGE also shows a regionally varying performance with $>0.8$ for stations in the Nile basin and $<0$ in Tanzanian basins (Table S4). Overall, the monthly streamflow has a median KGE of 0.6. The time series plots of monthly flows (after bias correction) for selected stations are shown in Fig. S2.

Figure 3 presents the shape of the flow climatology as the percentage mean monthly contribution to the annual flow for six selected stations (see Fig. S3 for the remaining stations). In common with the streamflow correlations presented earlier, the shapes of the flow climatology vary across the subregions. The flow climatologies of the observed and simulated streamflow agree for the Eddiem 

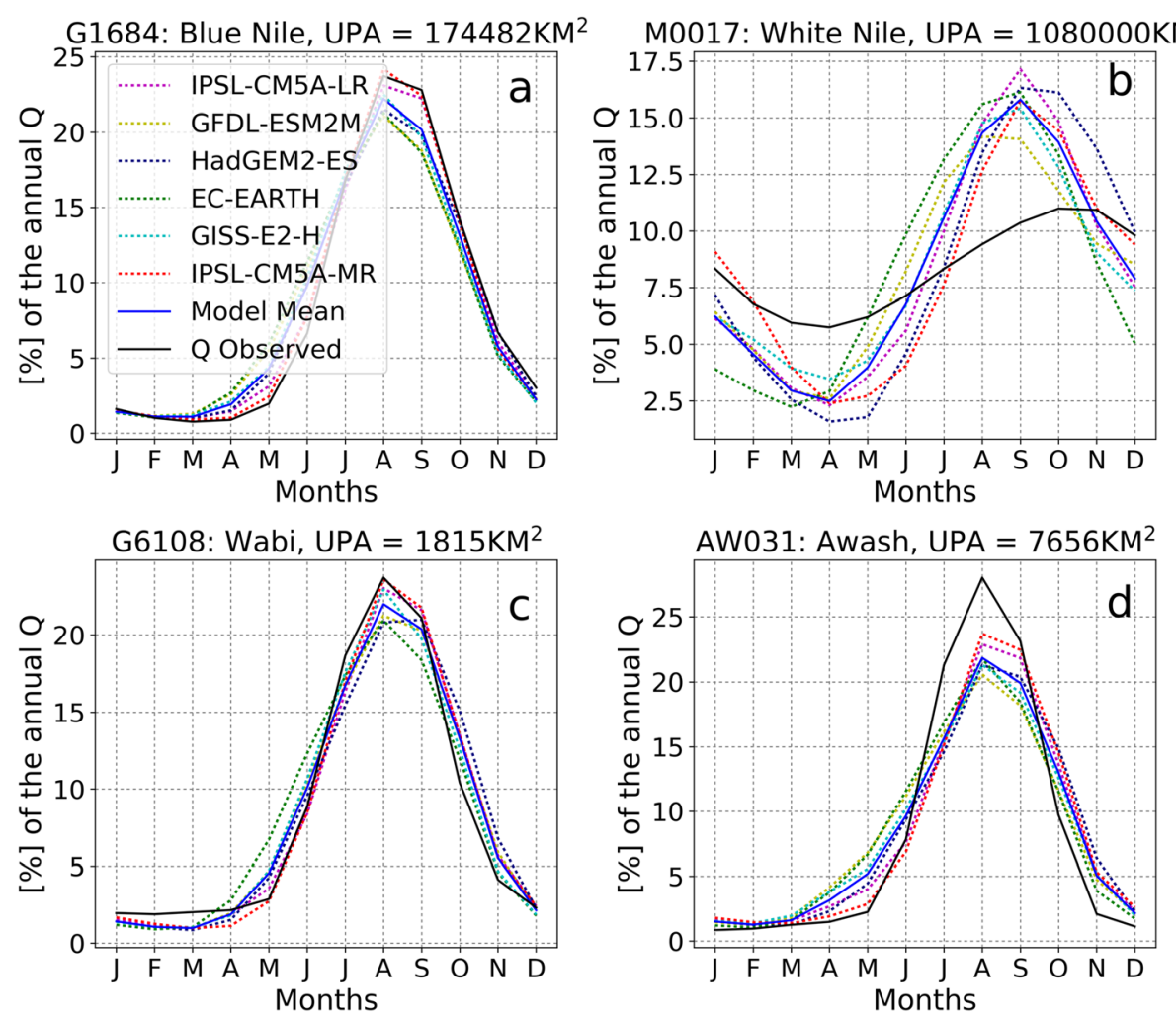

G6088: Shabelle, UPA $=215380 \mathrm{KM}^{2}$

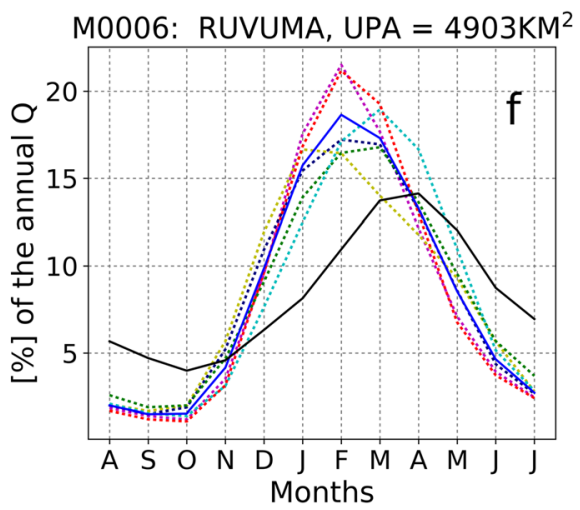

Fig. 3 a-f Streamflow seasonality for selected stations. The seasonality and monthly climatology are calculated over the 1976-2005 period

station (G1684, 3A), with all simulations correctly indicating the peak flow in August. Overall, the IPSL-CM5A SST-forced simulations have the best shape agreement, while EC-EARTH and GFDLESM2M display the least agreement. The peak flow month (August) was also correctly captured by all simulations for Wabi station (Fig. 3c) in the Upper Ghibe river basin and Hombole station (Fig. $3 d$ ) in the Awash river basin.

However, for the remaining selected stations (Fig. 3), the modelled streamflow could not match either the shape of the observed climatology or the peak flow month. All simulations 
indicate the peak flow in September for Makalal station (Fig. 3b) in the White Nile, 1 month earlier that the observed peak flow. As indicated earlier, the flow at this station is highly regulated by Lake Victoria. All simulations underestimate the relative contribution of the peak to the annual flow for the Hombole station (Awash). For Afgooye station (Shabelle, Fig. 3e), there is large disagreement between simulations on both the flow seasonality and the relative monthly contributions. Three simulations (IPSL-CM5A-LR, IPSL-CM5A-LR and HadGEM2-ES) miss the MAM flows and indicate most of the total annual flow occurring during July-October. The other three simulations correctly capture the bimodality of the flow for this station, but they relatively amplify the flow contribution during the MAM (ECEARTH and GFDL-ESM2M) or OND (GISS-E2-H SST) seasons. While the simulations appear to agree on the unimodality of the flow season for Ruvuma river in Tanzania (Fig. 3f), they disagree on the peak flow month, ranging from January (GFDL-ESM2M) to March (GISS-E2-H). All of those are earlier than the observed peak flow in April. The streamflow simulations fail to capture the high flows in March-May for all stations in Tanzania.

The overall streamflow evaluation highlights the challenge of climate impact assessment in the GHA region that has such a highly variable hydroclimate. This is especially evident in the southern part of the region, where the monthly correlation is low and the streamflow seasonality is not well captured. Even the high-resolution climate simulations have a mixed performance in this sub-region. Nevertheless, our findings further underscore that an accurate climate impact assessment requires locally relevant climate models.

\subsection{Streamflow projections}

\subsubsection{Changes in mean flow}

Figure 4 shows the percent change in long-term mean streamflow for 2040s compared to the baseline period for each simulation driven by the SSTs from the six CMIP5 models. The simulations show different sign and magnitude of streamflow change across the GHA region. The changes can generally be classified into three groups: (1) streamflow decrease in most parts of the GHA region (EC-EARTH and IPSL-SM5A-MR), (2) a large decrease in the southern (Tanzania) but a small change in northern parts of the GHA region (HadGEM2-ES SST) and (3) a decrease in the northern (Sudan and northern Ethiopia), increase in the equatorial and decrease in the southern parts of the region (IPSL-CM5A-LR, GFDLESM2M and GISS-E2-H).

The magnitude of streamflow changes varies across the different climate simulations. ECEARTH produced the driest projection with more than $25 \%$ streamflow reduction in large parts of the GHA region, especially the Juba-Shabelle and Awash rivers. Conversely, GISSE2-H and GFDL-ESM2M produced projections of more than $25 \%$ increase in equatorial part of the region and the Juba-Shabelle basin. It is worth noting that the disagreement between the EC-EARTH and GISS-E2-H on the direction of streamflow change in the Juba-Shabelle occurs despite the fact that both runs correctly capture the bimodality of the flow season in the basin. Mean streamflow (averaged over the six simulations) shows a -10 to $5 \%$ change in Ethiopia, up to $25 \%$ increase in parts of the equatorial region and up to $25 \%$ decrease in the southern and western parts of the GHA region.

While the pattern generally remains the same through the twenty-first century, the magnitude of the streamflow change intensifies in 2080s (2070-2099, Fig. 5). Two simulations (ECEARTH and IPSL-SM5A-MR) show the largest mean streamflow decrease ( -50 to $-80 \%)$ 


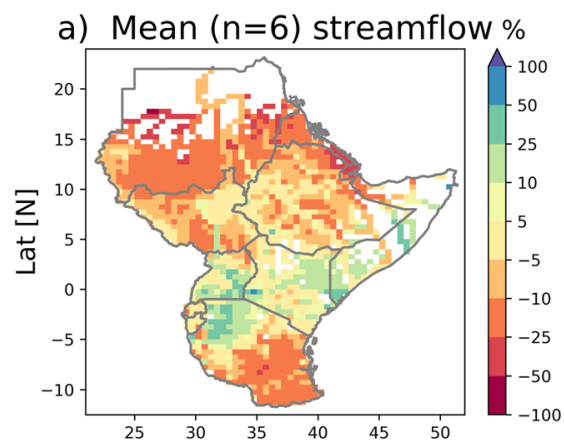

\section{Mean streamflow changes in 2040s}
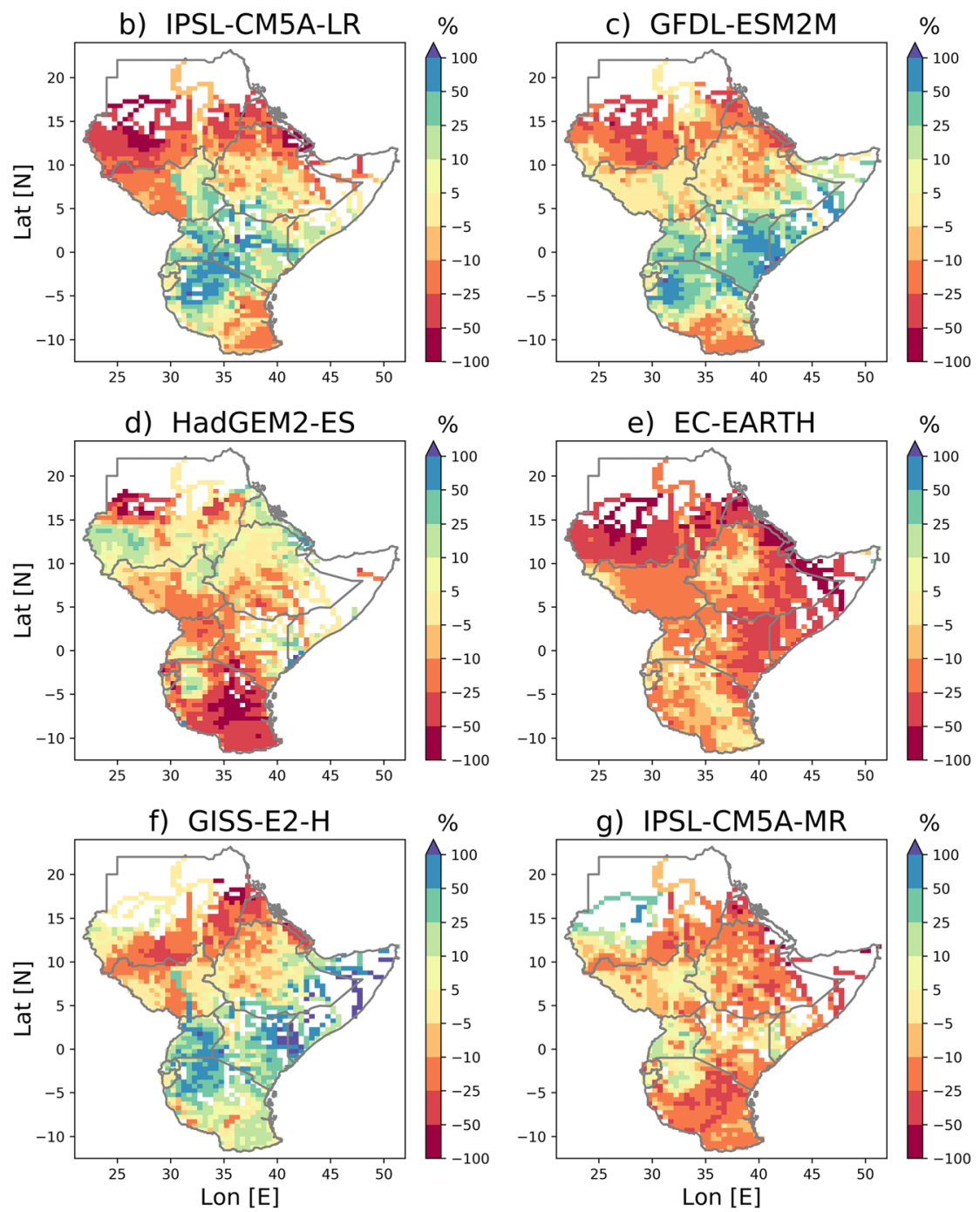

Fig. 4 a-g Projected changes in streamflow magnitude in 2040s compared to the baseline (1976-2005) shown for simulations forced with six SSTs (indicated) and the streamflow mean. Areas with $Q$ values less than $5 \mathrm{~m}^{3} / \mathrm{s}$ (white) are filtered out 


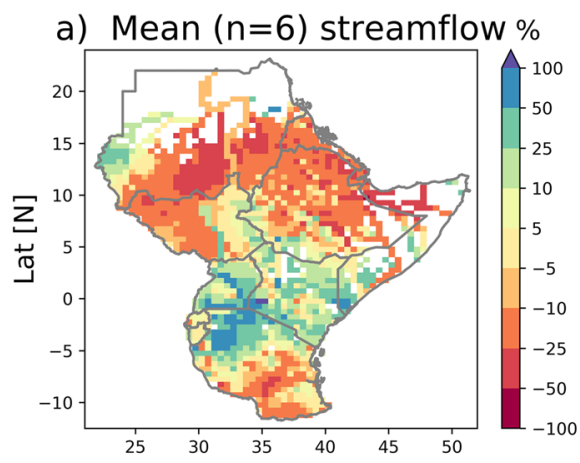

\section{Mean streamflow changes in 2080s}

b) IPSL-CM5A-LR

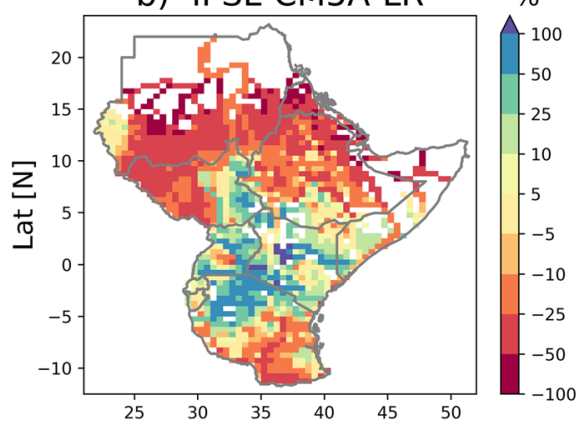

d) HadGEM2-ES
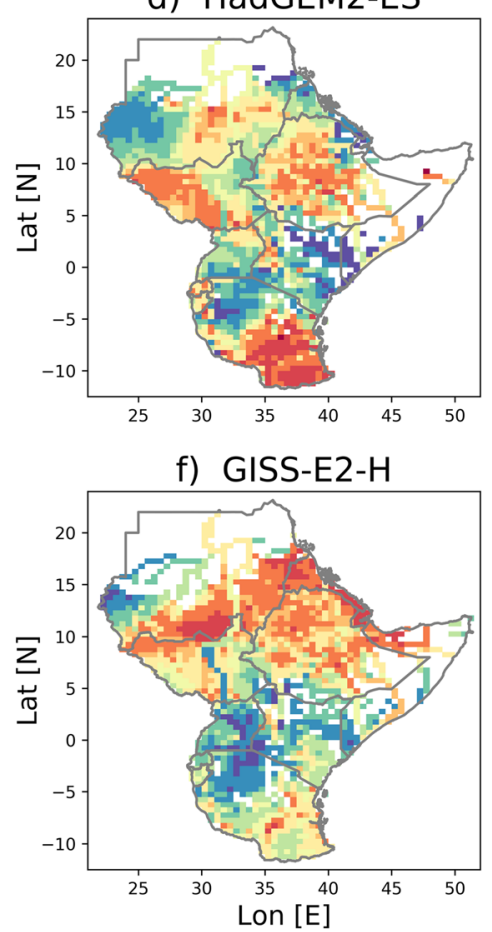

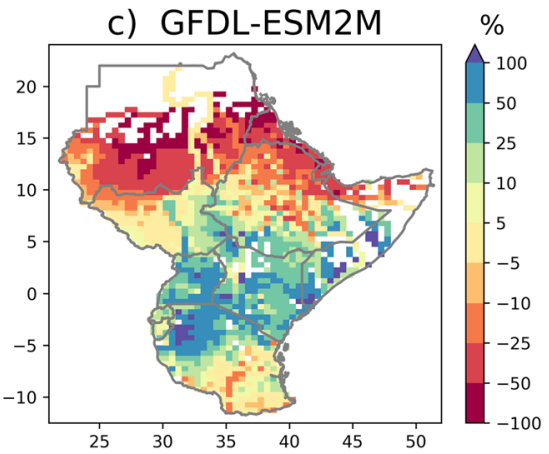

e) EC-EARTH

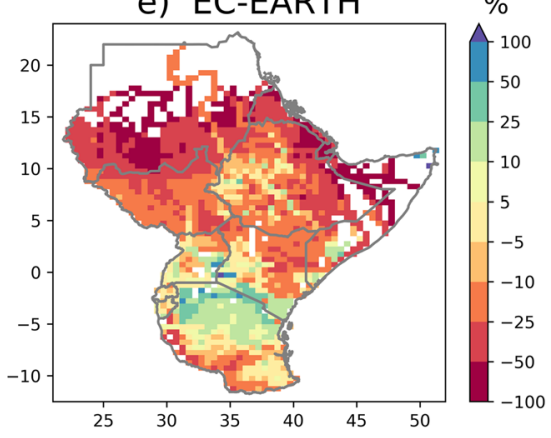

g) IPSL-CM5A-MR

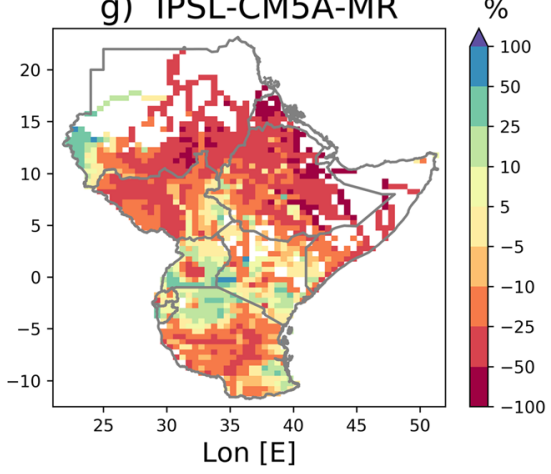

Fig. 5 Same as Fig. 4 but for 2080s 
for Ethiopia and Sudan, resulting in substantial streamflow reductions in the Nile, Awash and Juba-Shabelle rivers. Two simulations (IPSL-CM5A-LR and GFDL-ESM2M) show large streamflow increases (up to $100 \%$ ) in the equatorial regions, but decreases (>50\%) in large parts of Ethiopia and in Sudan. The HadGEM2-ES and GISS-E2-H forcings produce large flow increases in most parts of the GHA region but show slight decreases in central and northern Ethiopia.

The ensemble mean shows more than a $10 \%$ increase in the equatorial part of the region, but a decrease in Blue Nile and Shabelle basins. The flow increase is in agreement with previous studies that reported a significant increase in rainfall in the equatorial part of the region in 2080s using ensemble mean of 4 CMIP5 models with RCP8.5 scenarios including EC-EARTH and HadGEM2-ES (Endris et al. 2016).

\subsubsection{Changes in seasonal flows}

Figure 6 shows the projected streamflow change in the summer season (JJAS) for 2080s. As noted earlier, the JJAS season is the main rainy season in the northern part of the GHA region, which includes Blue Nile, Upper Awash, Ghibe and Baro river basins. Overall, the simulations show a large flow decrease for those basins in 2080s compared to the baseline period. All simulations indicate a 10-50\% flow decrease in Awash, Ghibe and Juba-Shabelle basins. The EC-EARTH shows the driest future during the JJAS season in the whole GHA region. Similarly, the IPSL-CM5A-MR and IPSL-CM5A-LR produced substantial flow decrease in the northern part of the region including Ethiopia, South Sudan and Sudan. They, however, show substantial flow increase in equatorial regions with a dry JJAS season. The GFDLESM2M follows a similar trend. The remaining simulations (HadGEM2-ES and GISS-E2-H) show an increase in flow ( $>25 \%$ ) in large parts of the GHA region except central Ethiopia, where a flow decrease is projected. The decrease in the northern part of the GHA region is in agreement with the study of Endris et al. (2016), which reported a rainfall decrease during JJAS. The mean of the six simulations shows a flow decrease (ranging from -5 to $-50 \%$ ) in the major rivers in the region including Nile, Juba-Shabelle, Awash and Ghibe rivers. However, a modest to large flow increase $(10-50 \%)$ is projected in the equatorial regions during the JJAS season.

The mean streamflow change during the JJAS season in 2040s has the same general pattern as in 2080s (Fig. S4). Parts of the GHA region with projected flow increase (decrease) in 2080s also have the same increase (decrease) in 2040s, but the magnitude of the percentage change is smaller in 2040s. Interestingly, the HadGEM2-ES leads to inconsistent increasing/ decreasing trends across different parts of the region, specifically in Tanzania, Rwanda and Kenya.

Large disagreement between the six streamflow simulations is observed for projected streamflow changes in 2080s during the MAM season (Fig. 7). EC-EARTH again shows a drying trend in the MAM season in the majority of the GHA region with the eastern part of the region (Somalia, Kenya, eastern Ethiopia) having more than 50\% flow reduction in 2080s. The IPSL-CMA-LR and IPSLCMA-MR produce large increase (in some parts up to 100\%) in the equatorial region where the MAM season is one of the two rainy seasons. Conversely, they show a reduced flow in eastern Ethiopia, affecting the flows in the Awash and Shabelle rivers. The other three simulations (GFDLESM2M, HadGEM2-ES and GISS-E2-H) indicate large flow increase during the MAM season across the GHA region. This can be seen, for example, from the large flow increase in the Nile River during the MAM season. The ensemble mean shows an increase in streamflow in the equatorial part 


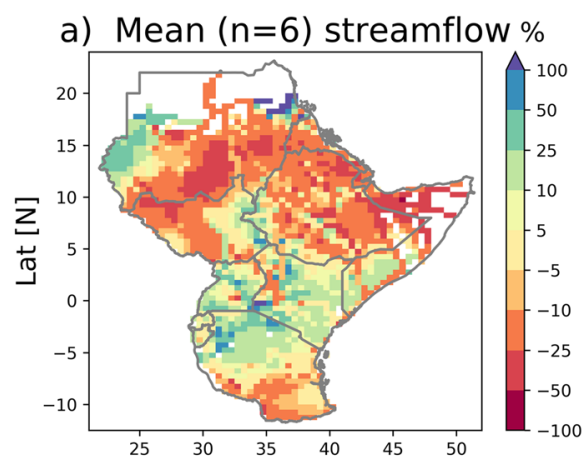

\section{JJAS streamflow changes} in 2080s
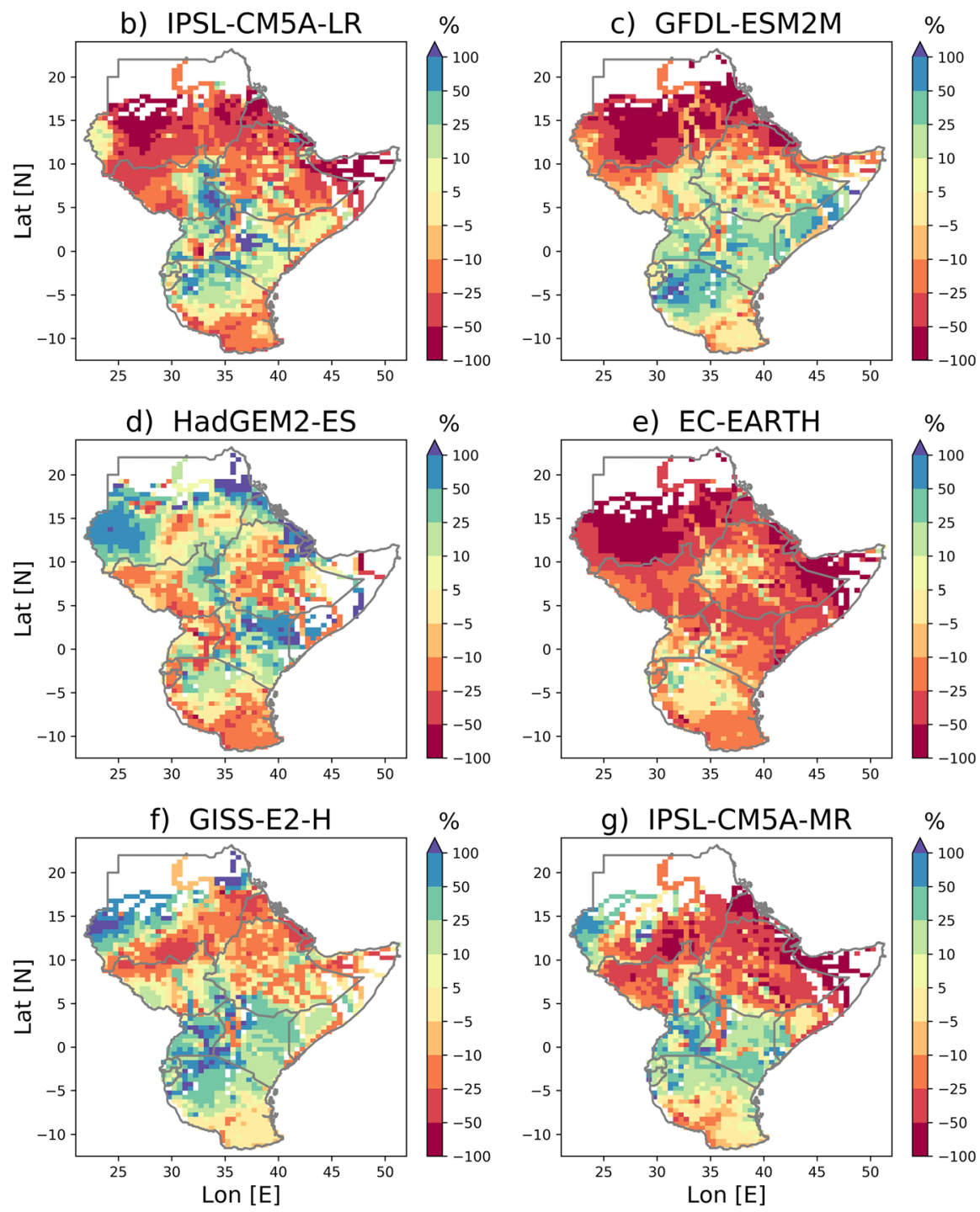

Fig. 6 a-g Projected changes in 2080s for the JJAS season 


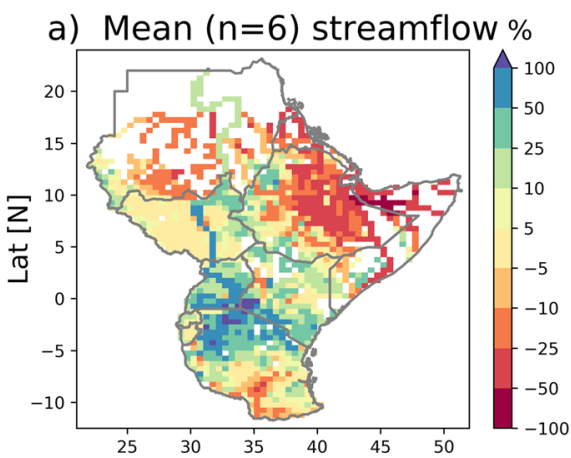

\section{MAM streamflow changes in 2080s}

b) IPSL-CM5A-LR

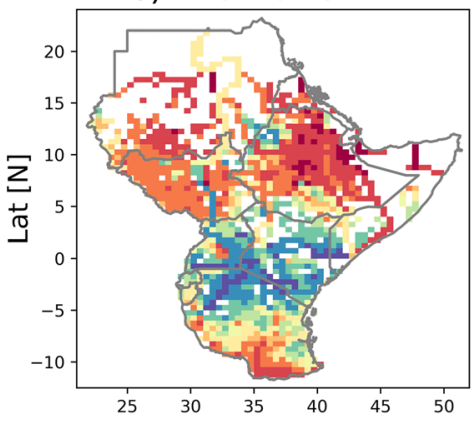

d) HadGEM2-ES
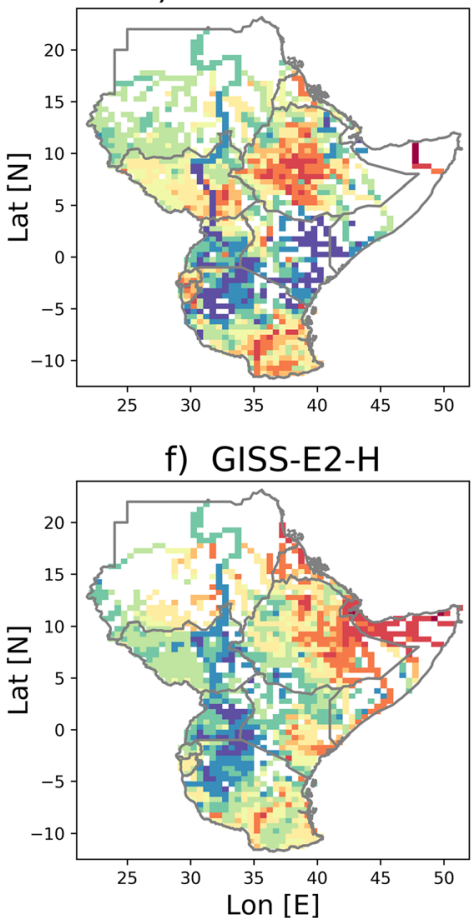

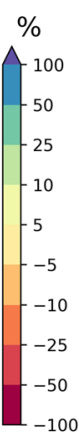

$\%$
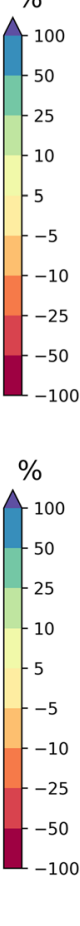

c) GFDL-ESM2M

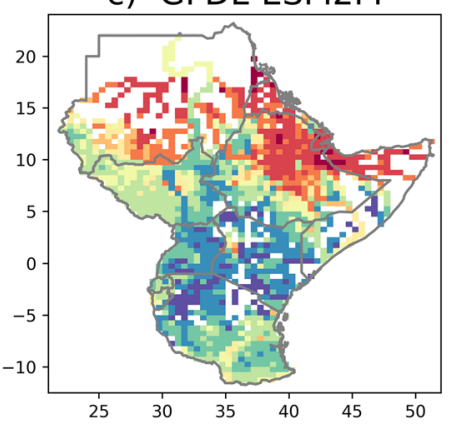

e) EC-EARTH
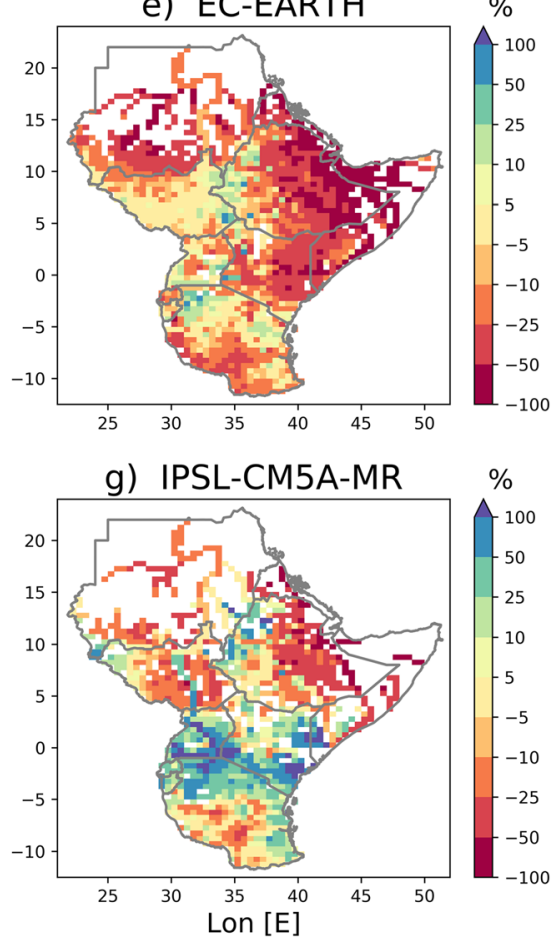

Fig. 7 Same as Fig. 6 but for the MAM season 
and a decrease in Ethiopia. The percentage flow change (increase or decrease) is larger during the MAM compared to the JJAS season.

For the 2040s (Fig. S5), the flow increase/decrease trend in MAM season is consistent with the 2080s for three simulations. The EC-EARTH essentially indicates the same pattern and trend, while IPSL-CM5A-LR and GFDL-ESM2M retain the same pattern but with lower percentage changes in 2040s. The remaining three simulations show inconsistent change patterns. The HadGEM2-ES shows a large flow increase in the equatorial region in 2080s but decrease in 2040s; the GISS-E2-H shows a flow decrease in south-eastern Ethiopia in 2080s but large increase in 2040s; and IPSL-CM5A-LR shows a flow increase in the equatorial region (e.g. Kenya) in 2080s but decrease in 2040s compared to the baseline period. The mean of the six simulations shows a consistent flow trend (decrease in northern and increase in the equatorial parts) but with lower change magnitudes in 2040s compared to 2080s.

Figure 8 shows the percentage change in streamflow during OND, the short rainy season. The streamflow simulations show different flow trends during the OND season across the GHA region. Three simulations (GFDL-ESM2M, HadGEM2-ES and GISS-E2-H) show large streamflow increase (some exceeding 100\%) in 2080s, while two simulations (IPSL-CM5ALR and EC-EARTH) indicate a modest flow increase in western Kenya and parts of Somalia. Conversely, IPSL-CM5A-MR shows a substantial flow decrease in the equatorial region during the OND season. IPSL-CM5A-MR also shows an extensive drying trend during the OND season over large parts of the GHA region. The OND streamflow changes in 2040s (Fig. S6) have a consistent trend with those in 2080s. The ensemble mean shows a streamflow increase in the equatorial sub-region during the OND season.

\subsubsection{Changes in extreme flows}

Figure 9 presents the low (Q95) and high (Q05) flow magnitudes for the baseline period and the percent change in 2040s and 2080s. The Q95 and Q05 here were computed based on the streamflow mean for the six simulations. A small change $( \pm 5 \%)$ is projected in the low flow magnitude in the 2040s in the GHA region, except in Tanzania where the low flow reduction is higher, ranging 10-25\% (Fig. 9b). However, a higher reduction (5-25\%) in low flow is projected in 2080s for the northern parts of the GHA region (including Ethiopia) and for Tanzania (Fig. 9c). This has important implications on the water availability in river channels during the dry seasons and may severely impact water supply in the rapidly growing populations of Ethiopia and Tanzania, which are expected to have a combined population of 0.55 billion (3.3 times the current) at the end of the twenty-first century (United Nations 2017a).

The relative change in high flow magnitude is more pronounced. It is projected to decrease by up to $10 \%$ in 2040s for major rivers such as the Blue Nile, Shabelle, Awash and Ghibe (Fig. $9 \mathrm{e})$. Conversely, it is projected to increase (5-25\%) in the equatorial parts of the region. In 2080s, the percent change in high flows is higher, with flows in the major rivers projected to decrease by up to $25 \%$ of the baseline, and the equatorial part will experience substantial flow increase (Fig. 9f). The high flow reduction in Ethiopia is consistent with the reduction in mean flow across all seasons presented earlier. The reduction in extreme high flows, which is the main source of groundwater recharge in East Africa and semi-arid environments (Döll and Fiedler 2008; Taylor et al. 2013), will negatively impact groundwater recharge in large parts of the GHA region. 


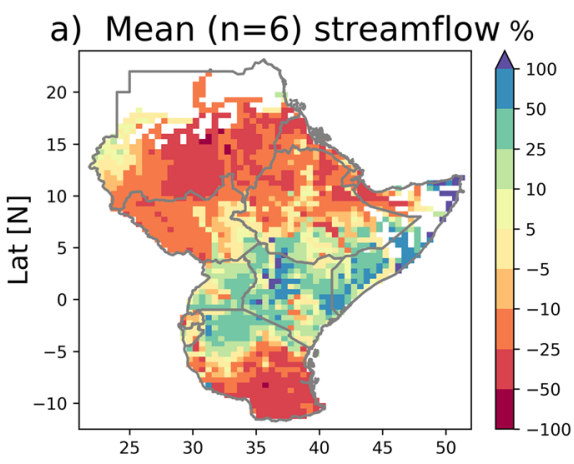

\section{OND streamfow changes in 2080s}

b) IPSL-CM5A-LR

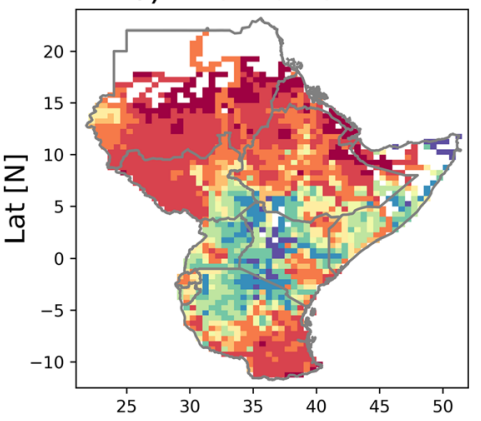

d) HadGEM2-ES
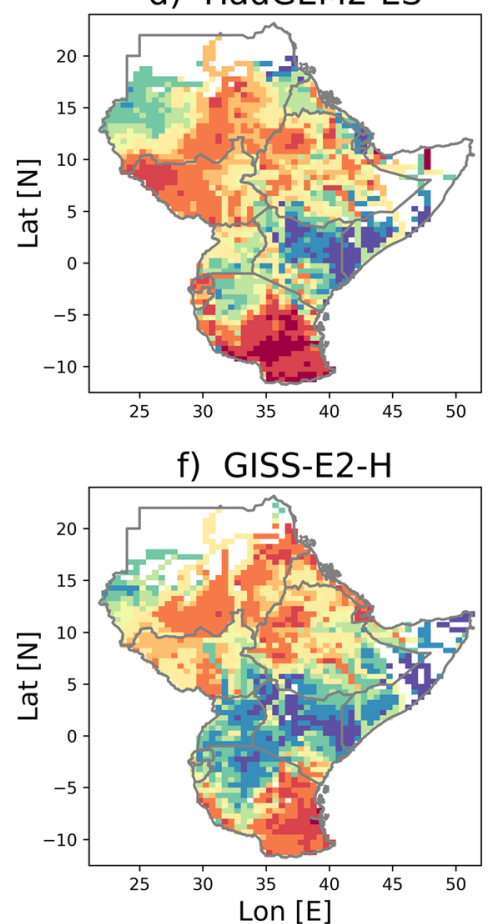

$\%$

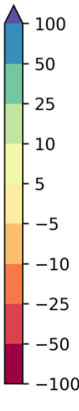

$\%$
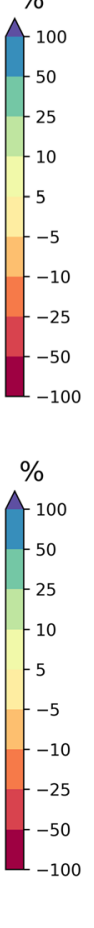

c) GFDL-ESM2M

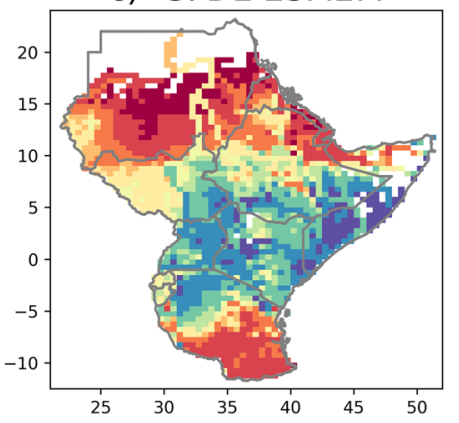

e) EC-EARTH
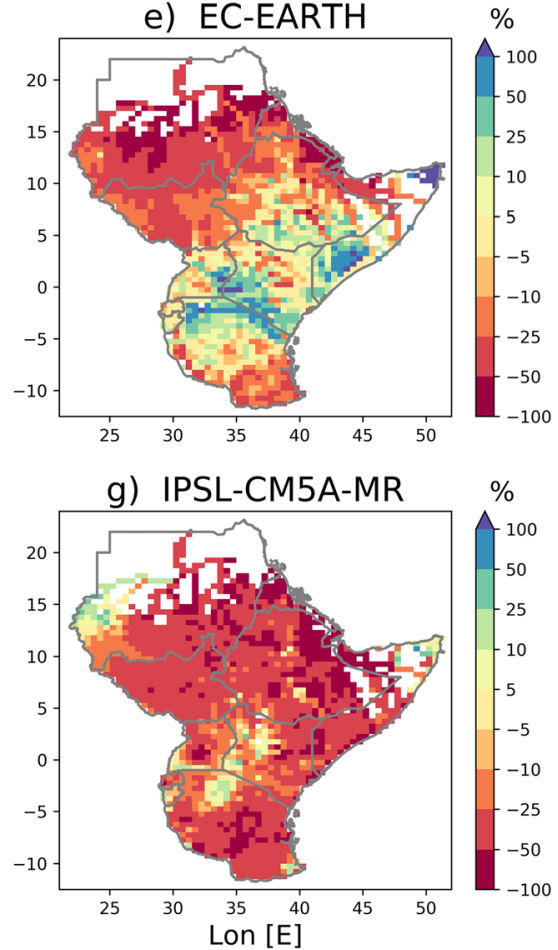

Fig. 8 Same as Fig. 6 but for the OND season 

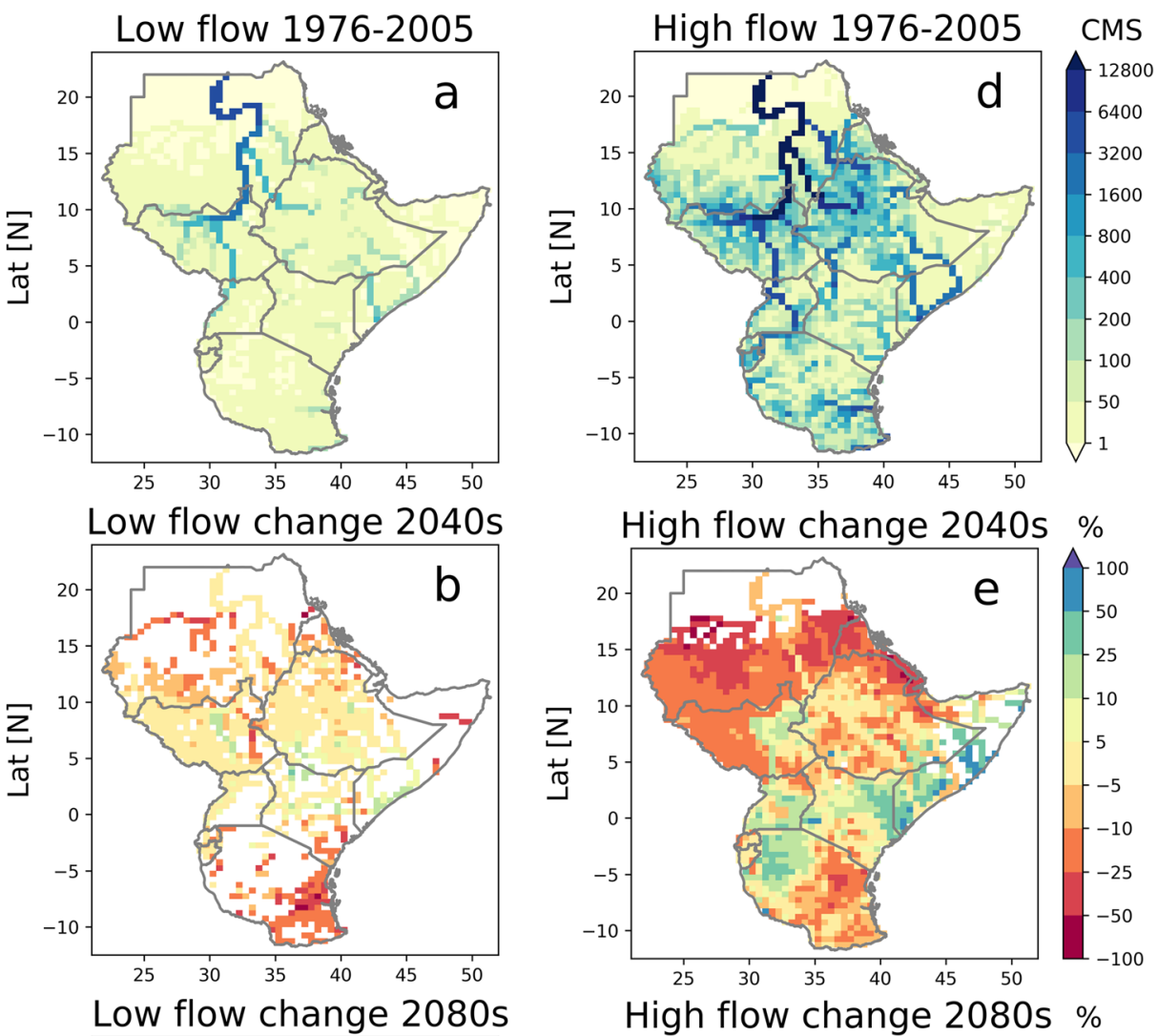

High flow change 2040s
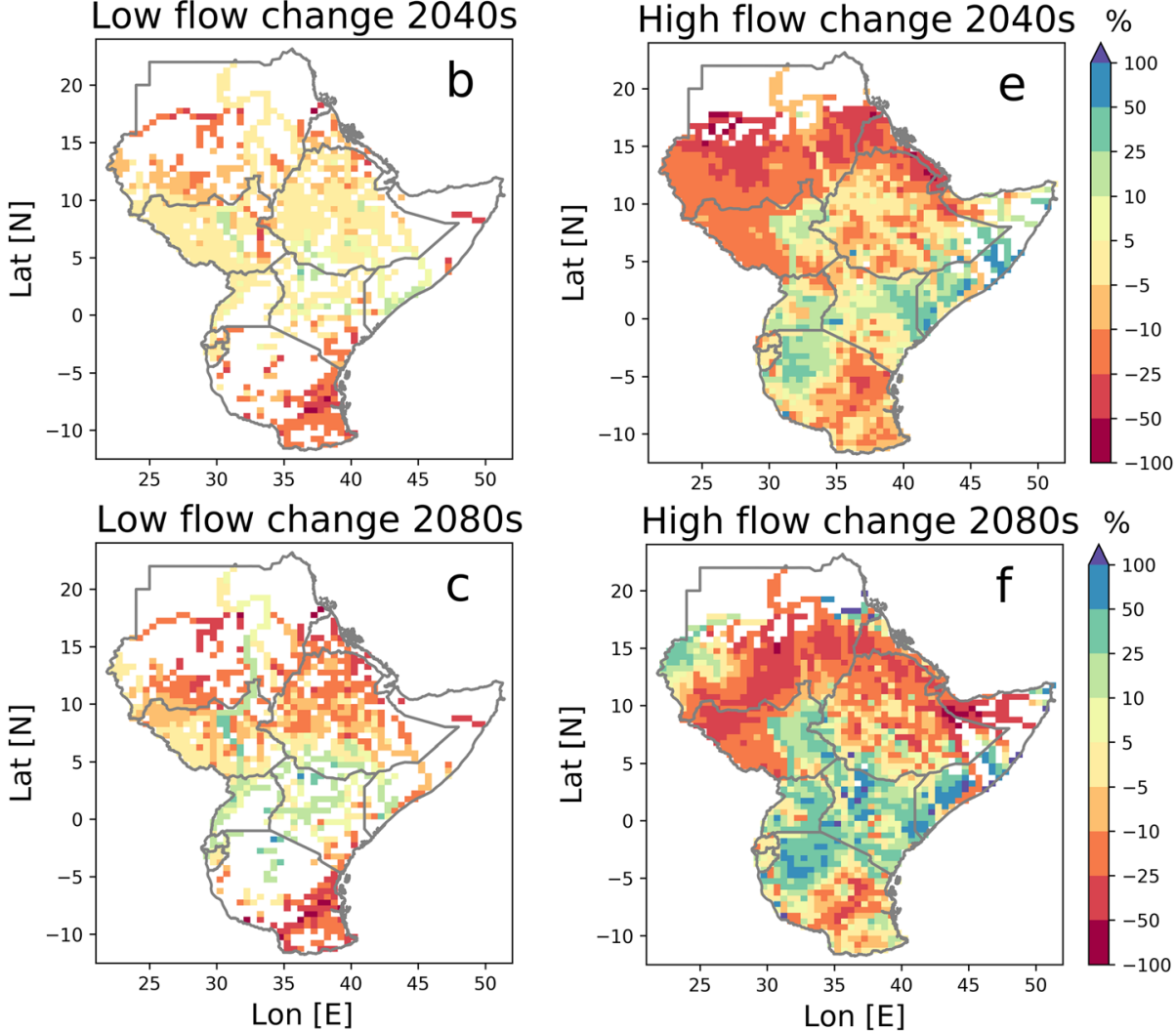

High flow change 2080s \%

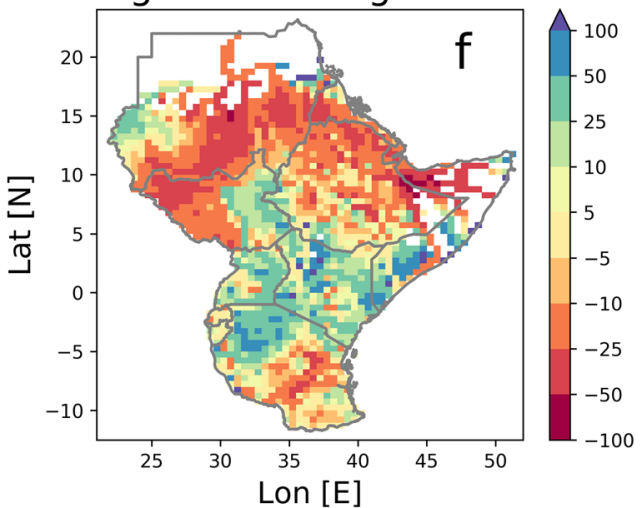

Fig. 9 The a-c low (Q95, left panel) and $\mathbf{d}-\mathbf{f}$ high (Q05, right panel) flow magnitudes during the baseline and changes in low and high flows for 2040s (middle panel) and 2080s (bottom panel). The low and high flows were calculated from the mean streamflow from six simulations. Areas with $Q$ values less than $5 \mathrm{~m}^{3} / \mathrm{s}$ are filtered out

\subsubsection{SST influence on streamflow}

Studies report that East African rainfall variability is linked to the SST variations in the tropics; specifically, the variations in western and central Pacific and Indian Oceans have a strong influence on the MAM and OND rainfall patterns in the GHA (Black 2005; Bhattacharjee and Zaitchik 2015; 
Funk et al. 2014). The MAM is the planting season in the region and low rainfall conditions during this period have led to food insecurity and malnutrition in the region. The GHA spring droughts are linked to the strengthening of the Walker circulation, whose variations are closely associated with El Niño/Southern Oscillation (Vecchi et al. 2006; Williams and Funk 2011). The relative warming of western Pacific and cooling of central Pacific intensifies the Pacific branch of the Walker circulation, creating low (high) pressure system in west (central) Pacific Ocean (Funk et al. 2013). Previous studies have shown that the strengthening of this east-west atmospheric circulation in the Pacific can lead to decreased MAM rainfall conditions in eastern Africa (Hoell and Funk 2014; Funk et al. 2015).

Here. we compare the SSTs from the CMIP5 models with Hadley Centre Sea Ice and Sea Surface Temperature dataset (HadISST) (Rayner et al. 2003) during the 1976-2005 period. The CMIP5 models have wide-ranging SST biases in different parts of the globe (Fig. S7). Figure 10 shows the area-average SST over the west Pacific $\left(10^{\circ} \mathrm{S}-10^{\circ} \mathrm{N}, 110^{\circ}-150^{\circ} \mathrm{E}\right)$ and Niño-4 (central Pacific) region $\left(5^{\circ} \mathrm{S}-5^{\circ} \mathrm{N}, 160^{\circ} \mathrm{E}-150^{\circ} \mathrm{W}\right)$ and the difference between SST over the two regions. We focus on these regions due to the reported sensitivity of the MAM season rainfall in the equatorial GHA to the SST in the regions. EC-EARTH has consistently colder SST in west Pacific

a) WP SST

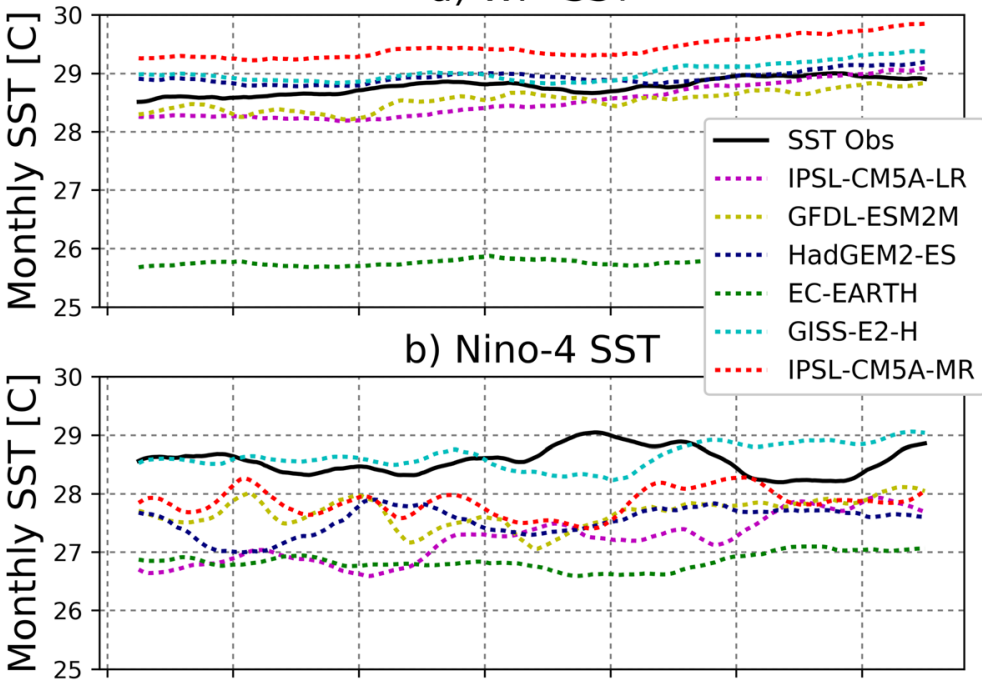

c) Nino-4 minus WP SST

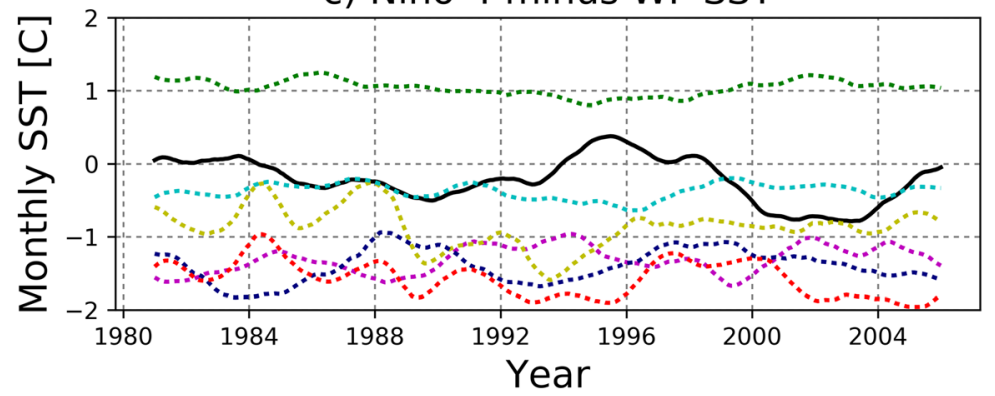

Fig. 10 Five-year running mean of the monthly SST over Nino-4 (a), west Pacific (b) and the difference between Nino-4 and west Pacific (c) 
with a mean value of $-2.98{ }^{\circ} \mathrm{C}$ during the 1976-2005 period compared to the observation, while IPSL-CM5A-MR has warmer bias with mean $0.65^{\circ} \mathrm{C}$ (Fig. 10a). Other SST values closely match the observation over the west Pacific $\left( \pm 0.25{ }^{\circ} \mathrm{C}\right)$. Over the Niño-4 region, models have largely colder SST than the observation with long-term mean values ranging from an average of $-0.71{ }^{\circ} \mathrm{C}$ (IPSL-CM5A-MR) to $-1.72{ }^{\circ} \mathrm{C}$ (EC-EARTH). Only GISS-E2-H has slightly warmer SST $\left(0.31{ }^{\circ} \mathrm{C}\right)$ than observed values over the Niño-4 region. The SST differences between the two Pacific regions (Fig. 10c) show larger differences between the models. EC-EARTH shows a consistently warmer central Pacific with a long-term mean of $+1.04{ }^{\circ} \mathrm{C}$, which can weaken the Walker circulation associated with increasing MAM rainfall in the equatorial GHA region. All other models and the observed record (except in the early 1990s) show a warmer west Pacific.

In agreement with previous findings (Funk et al. 2014; Funk et al. 2015), the MAM streamflow appears to be linked to the SST difference between the Nino-4 region and western Pacific. Figure 11 presents the time series of the MAM streamflow and SST (Nino-4 minus western Pacific) for a selected station in the Juba-Shabelle river basin in the equatorial GHA region. Simulations with the lowest SST difference between Nino-4 and western Pacific SST have the lowest MAM streamflow in the basin, while the simulation with the highest SST difference (EC-EARTH) largely produced

a) MAM streamflow G6088

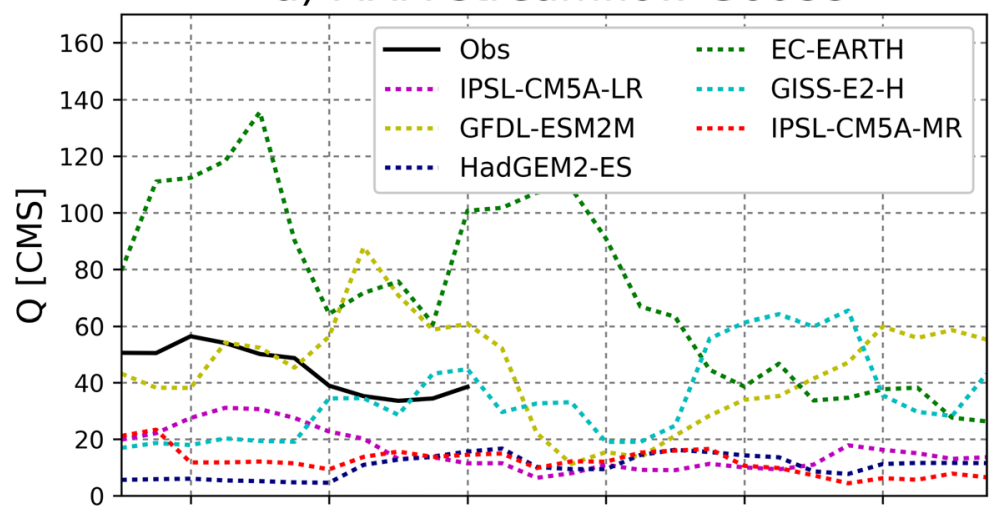

b) Nino-4 minus WP SST

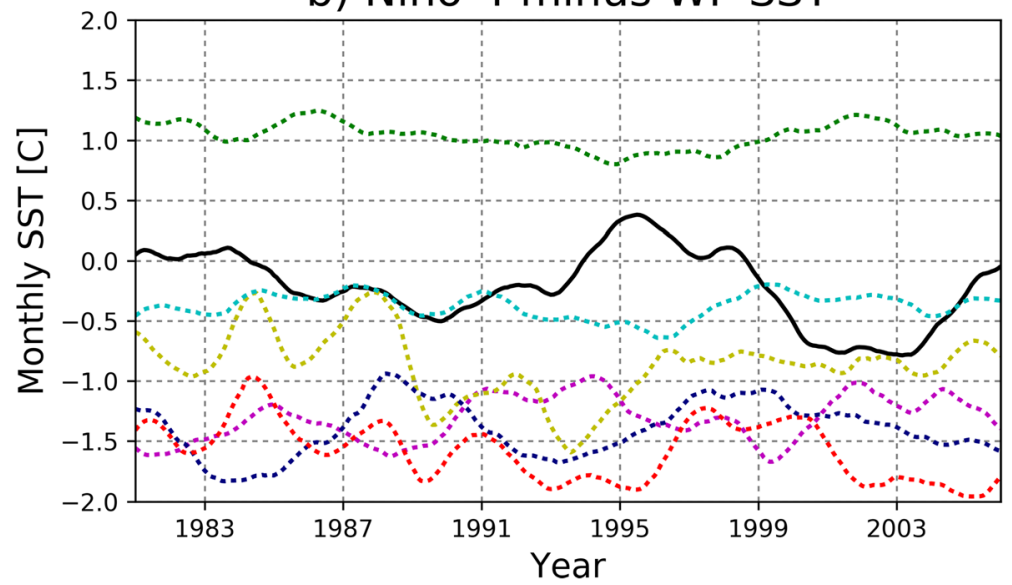

Fig. 11 MAM streamflow variation with SST. Five-year running mean of MAM streamflow at a selected station Afgooye, Juba-Shabelle (a) and the difference between Nino-4 and west Pacific (b) 
the largest MAM streamflow. However, the reason behind the sudden decline in EC-EARTH streamflow after 1995 is unclear.

\section{Discussion}

\subsection{Streamflow uncertainty}

The potential impacts of climate change on streamflow have large uncertainty arising from a cascade of errors in the modelling chain (Wilby and Dessai 2010; Clark et al. 2016). While the aim of this paper is not to characterise the uncertainty in each component of the modelling chain, we highlight the potential contribution of each modelling component. The simulated streamflow presented here can be affected by uncertainties in the greenhouse gas concentration considered (RCP8.5), the climate model (ECEARTH3-HR), the SST forcing (from CMIP5 runs) and the hydrological model (LISFLOOD).

The Paris Agreement aims to limit the increase in global mean surface air temperature well below $2{ }^{\circ} \mathrm{C}$ relative to preindustrial levels and to pursue efforts to limit it to $1.5^{\circ} \mathrm{C}$ (UNFCCC COP 21 2015). If this, which requires a rapid reduction of anthropogenic emissions, is to be achieved, the high-end emission scenario corresponding to the radiative forcing of $8.5 \mathrm{~W} / \mathrm{m}^{2}$ (RCP8.5) used here is less likely to occur. However, the "business as usual" current trajectory indicates the $1.5{ }^{\circ} \mathrm{C}$ warming is likely to be reached between 2030 and 2052, far earlier than the Paris Agreement (IPCC 2018). For the six SST projections used here, the average year of exceeding $1.5^{\circ} \mathrm{C}$ is 2024 , which is comparable with the current climate trajectory.

The EC-EARTH3-HR climate model, which is a member of the upcoming CMIP6 experiments, is an improved version of the previous CMIP5 model (EC-EARTH2). It has an increased resolution and improved microphysics to better represent tropical precipitation (Wyser et al. 2017). The LISFLOOD model parameters were not calibrated for the study basins and lakes and reservoir modules were deactivated. This influences the accuracy of the streamflow simulations; however, since the same model setup and the same set of model parameters were used for the present and future simulations, the relative streamflow changes due to climate change are only marginally affected. The differences in streamflow seasonality, variability and trends between the six simulations indicate the sensitivity of the region's streamflow to SST forcing, as discussed in Section 4.2.4.

The climate models' uncertainty in reproducing precipitation in the GHA region is well documented in the literature (Rowell et al. 2015; Dosio et al. 2015). The CMIP5 models and the regional climate models show large error in the projections of rainfall trends and seasonality in the region. Since our analysis uses an improved version of the previous model, we believe that this study is a step in the right direction to identify and reduce the uncertainty in the climate projections of the GHA region.

Two key issues related to future streamflow changes that require further research are quantifying (1) the impacts of land use change and other man-made influences (e.g. dams, abstractions) on streamflow and (2) the impacts of different greenhouse gas emissions and warming levels on streamflow. In addition, comparing the outputs from the EC-EARTH3-HR with those from the upcoming CMIP6 family of climate models may help better understand the projection uncertainty.

\subsection{Implications for water resources}

Rivers remain the most important source of water supply in the GHA region. Even though the streamflow projections differ in some respects, they all agree on flow reduction in all major 
rivers of Ethiopia. This can have a negative effect on future water availability in the country. Hydroelectric power currently generated from Awash, Ghibe and Nile tributaries contributes to 94\% of the total 12.5 TWh of energy production in Ethiopia (Ethiopian Electric Power (EEP) 2017), which can potentially be affected by the future streamflow reduction. The depleted water availability in large parts of the GHA region also exposes the agriculture and pastoral community to an intensified water stress. The potential reduction in groundwater recharge as the result of the future decrease in extreme high flows can increase the risk of groundwater depletion, further impacting the water supply sources.

The majority of the streamflow simulations indicate increasing future flows in the equatorial subregion. It is worth considering two factors for water resources planning in the equatorial parts of the region. Firstly, the skill of modelled streamflow is relatively poor in the sub-region, with half of the ensemble members completely missing the bimodal season. Considering the poor performance in the historical streamflow, it appears questionable to trust the future projections in the equatorial subregion. Secondly, it is important to consider the rapidly growing water demand, which is already exceeding the available supply. Even with uncertain climate information, a better adaptation to current climate will likely make the water resource systems more resilient to future climate.

The reduced future streamflow in most of the transboundary river basins (including the Blue Nile, the Ghibe, the Shabelle and the Ruvuma) and other basins such as the Awash calls for policy decisions to improve water use efficiency and investment in water resources development.

\section{Conclusions}

We have analysed the streamflow response to climate change in the Greater Horn of Africa based on long-term streamflow produced using high-resolution climate simulations. We have evaluated the streamflow using flow data from 29 stations distributed across different subregions. Evaluation results show large sub-regional variations in the performance of simulated streamflow with monthly correlation ranging from $>0.9$ in the Blue Nile to $<0.4$ in Rovuma basin, Tanzania. The observed streamflow seasonality is well captured by all ensembles for rivers with JJAS high flow season. However, some simulations miss the March-May high flow season in the equatorial rivers with bimodal seasons.

Comparison of future streamflow with the baseline shows varying changes in flow magnitude, variability and trend across the GHA region. Overall, the ensemble mean shows a decrease $(-10$ to $-25 \%)$ in the long-term mean flow in Ethiopia and an increase $(>10 \%)$ in the equatorial part of the region in 2080s. Similarly, the region will experience a substantial change in high flows in 2080 s, with up to $-50 \%$ reduction in the northern and $50 \%$ increase in the equatorial parts. The ensemble mean also shows reduced monthly flow variability in 2080s during the JJAS season in the Blue Nile and during the MAM and OND seasons in the Shabelle basin.

Differences between the six streamflow simulations with regard to seasonality, trends and variability show the sensitivity of the region's flow to global SST forcing. Comparison with a global sea surface temperature dataset reveals a wide-ranging temperature bias in the SST used for generating the six streamflow ensembles. The use of the specified experimental design with a single of climate-hydrology model indicates that the SST biases may have contributed to the differences in the MAM peak flow detection among the ensembles. The six SST forcings also show different warming levels in 2080s compared to the baseline; however, more work is needed to establish the linkage between the warming trends and the streamflow changes in the 
GHA region. To this end, a detailed understanding of the relationship between the SST and streamflow may improve the predictability of streamflow in the region.

Acknowledgements We thank two anonymous reviewers for their constructive comments that have improved the presentation of the paper. We thank the Global Runoff Data Centre, Koblenz, Germany, for providing the streamflow data. Climate projections were kindly made available through the HELIX (High-End cLimate Impacts and eXtremes) Project, a European Union Seventh Framework Programme FP7/2007-2013 under grant agreement no. 603864 (www.helixclimate.eu).

Funding information This work is an output from the REACH programme (www.reachwater.org.uk) funded by UK Aid from the UK Department for International Development (DFID) for the benefit of developing countries (Aries Code 201880). However, the views expressed and information contained in it are not necessarily those of or endorsed by DFID, which can accept no responsibility for such views or information or for any reliance placed on them.

\section{Compliance with ethical standards}

Conflict of interest The authors declare that they have no conflict of interest.

Open Access This article is distributed under the terms of the Creative Commons Attribution 4.0 International License (http://creativecommons.org/licenses/by/4.0/), which permits unrestricted use, distribution, and reproduction in any medium, provided you give appropriate credit to the original author(s) and the source, provide a link to the Creative Commons license, and indicate if changes were made.

\section{References}

Alfieri L, Bisselink B, Dottori F, Naumann G, de Roo A, Salamon P et al (2017) Global projections of river flood risk in a warmer world. Earth's Future 5(2):171-182. https://doi.org/10.1002/2016EF000485

Awange, J. L., Khandu, Schumacher, M., Forootan, E., \& Heck, B. (2016). Exploring hydro-meteorological drought patterns over the Greater Horn of Africa (1979-2014) using remote sensing and reanalysis products. Advances in Water Resources, 94, 45-59. https://doi.org/10.1016/j.advwatres.2016.04.005

Barrios S, Ouattara B, Strobl E (2008) The impact of climatic change on agricultural production: is it different for Africa? Food Policy 33(4):287-298. https://doi.org/10.1016/j.foodpol.2008.01.003

Bhattacharjee PS, Zaitchik BF (2015) Perspectives on CMIP5 model performance in the Nile River headwaters regions. Int J Climatol 35(14):4262-4275. https://doi.org/10.1002/joc.4284

Black E (2005) The relationship between Indian Ocean sea-surface temperature and East African rainfall. Philos Trans R Soc A Math Phys Eng Sci 363(1826):43-47. https://doi.org/10.1098/rsta.2004.1474

Bontemps, S., Defourny, P., Bogaert, E.V., Arino, O., Kalogirou, V., Perez, J.R., 2011. GLOBCOVER 2009products description and validation report

Burek P, van der Knijff J, de Roo A (2013) LISFLOOD distributed water balance and flood simulation model, revised user manual 2013. In: JRC technical reports. Publications Office of the European Union, Luxembourg. https://doi.org/10.2788/24719

Clark MP, Wilby RL, Gutmann ED, Vano JA, Gangopadhyay S, Wood AW et al (2016) Characterizing uncertainty of the hydrologic impacts of climate change. Curr Climate Chang Rep 2(2):55-64. https://doi. org/10.1007/s40641-016-0034-X

Demory ME, Vidale PL, Roberts MJ, Berrisford P, Strachan J, Schiemann R, Mizielinski MS (2014) The role of horizontal resolution in simulating drivers of the global hydrological cycle. Clim Dyn. https://doi. org/10.1007/s00382-013-1924-4

Diro GT, Grimes DIF, Black E (2011) Teleconnections between Ethiopian summer rainfall and sea surface temperature: part I- observation and modelling. Clim Dyn 37(1):103-119. https://doi.org/10.1007/s00382010-0837-8

Döll P, Fiedler K (2008) Global-scale modeling of groundwater recharge. Hydrol Earth Syst Sci 12(3):863-885. https://doi.org/10.5194/hess-12-863-2008 
Dosio A, Panitz HJ, Schubert-Frisius M, Lüthi D (2015) Dynamical downscaling of CMIP5 global circulation models over CORDEX-Africa with COSMO-CLM: evaluation over the present climate and analysis of the added value. Clim Dyn 44(9-10):2637-2661. https://doi.org/10.1007/s00382-014-2262-X

Endris HS, Lennard C, Hewiston B, Dosio A, Nikulin G (2016) Future changes in rainfall associated with ENSO and IOD over eastern Africa. Clim Dyn 0(0):0. https://doi.org/10.1007/s00382-018-4239-7

Ethiopian Electric Power (EEP). (2017). Ethiopian electric power facts in brief 2017, http://www.eep.gov.et/eepprofile/

Fewnet (2017) East Africa Food Security Outlook February to September 2017. http://fews. net/sites/default/files/documents/reports/EA_OL_2017_03_final.pdf

Ficchì, A., Stephens, L., 2019 Climate variability alters flood timing across Africa. Geophys Res Lett 0. https://doi.org/10.1029/2019GL081988

Funk C, Husak G, Michaelsen J, Shukla S, Hoell A, Lyon B et al (2013) Attribution of 2012 and 2003-12 rainfall deficits in Eastern Kenya and Southern Somalia. Bull Am Meteorol Soc. https://doi.org/10.1175/BAMS-D13-00085.1

Funk C, Hoell A, Shukla S, Bladé I, Liebmann B, Roberts JB et al (2014) Predicting East African spring droughts using Pacific and Indian Ocean sea surface temperature indices. Hydrol Earth Syst Sci 18(12):4965-4978. https://doi.org/10.5194/hess-18-4965-2014

Funk C, Shukla S, Hoell A, Livneh B (2015) Assessing the contributions of East African and West Pacific warming to the 2014 boreal spring East African drought. Bull Am Meteorol Soc. https://doi.org/10.1175 /BAMS-D-15-00106.1

Gupta HV, Kling H, Yilmaz KK, Martinez GF (2009) Decomposition of the mean squared error and NSE performance criteria: implications for improving hydrological modelling. J Hydrol 377(1-2):80-91

Hirpa FA, Salamon P, Beck HE, Lorini V, Alfieri L, Zsoter E, Dadson SJ (2018) Calibration of the Global Flood Awareness System (GloFAS) using daily streamflow data. J Hydrol 566:595-606. https://doi.org/10.1016/j. jhydrol.2018.09.052

Hoell A, Funk C (2014) Indo-Pacific sea surface temperature influences on failed consecutive rainy seasons over eastern Africa. Clim Dyn 43(5-6):1645-1660. https://doi.org/10.1007/s00382-013-1991-6

Hohenthal J, Minoia P (2017) Social aspects of water scarcity and drought. In: Handbook of drought and water scarcity: principles of drought and water scarcity, pp 607-626. https://doi.org/10.1201/9781315404219

IPCC. (2018). IPCC special report on the impacts of global warming of $1.5{ }^{\circ} \mathrm{C}$-summary for policy makers. Retrieved from http://www.ipcc.ch/report/sr15/

IWMI. (2007). Trends in water and agricultural development. In D. Molden, K. Frenken, R. Barker, C. De Fraiture, B. Mati, M. Svendsen, ... C. M. Finlayson (Eds.), Water for food, water for life : a comprehensive assessment of water management in agriculture. Earthscan. Retrieved from http://horizon.documentation. ird.fr/exl-doc/pleins_textes/divers 15-08/010050288.pdf

Kumssa A, Jones JF, Williams JH (2009) Conflict and human security in the North Rift and North Eastern Kenya. Int J Soc Econ 36:1008-1020. https://doi.org/10.1108/03068290910984786

Mekonnen MM, Hoekstra YA (2016) Four billion people experience water scarcity. Sci Adv 2(2):1-7. https://doi. org/10.1126/sciadv.1500323

Naumann G, Alfieri L, Wyser K, Mentaschi L, Betts RA, Carrao H et al (2018) Global changes in drought conditions under different levels of warming. Geophys Res Lett 45(7):3285-3296. https://doi.org/10.1002 /2017GL076521

Nicholson SE (2014) A detailed look at the recent drought situation in the Greater Horn of Africa. J Arid Environ 103:71-79. https://doi.org/10.1016/j.jaridenv.2013.12.003

Otieno VO, Anyah RO (2013) CMIP5 simulated climate conditions of the Greater Horn of Africa (GHA). Part II: projected climate. Clim Dyn 41(7-8):2099-2113. https://doi.org/10.1007/s00382-013-1694-z

Rayner NA, Parker DE, Horton EB, Folland CK, Alexander LV, Rowell DP et al (2003) Global analyses of sea surface temperature, sea ice, and night marine air temperature since the late nineteenth century. J Geophys Res 108. https://doi.org/10.1029/2002JD002670

Rowell DP, Booth BBB, Nicholson SE, Good P (2015) Reconciling past and future rainfall trends over East Africa. J Clim 28(24):9768-9788. https://doi.org/10.1175/JCLI-D-15-0140.1

Shiferaw A, Tadesse T, Rowe C, Oglesby R (2018) Precipitation extremes in dynamically downscaled climate scenarios over the Greater Horn of Africa. Atmosphere 9(3). https://doi.org/10.3390/atmos9030112

Taylor RG, Todd MC, Kongola L, Maurice L, Nahozya E, Sanga H, Macdonald AM (2013) Evidence of the dependence of groundwater resources on extreme rainfall in East Africa. Nat Clim Chang 3(4):374-378. https://doi.org/10.1038/nclimate1731

Thielen J, Bartholmes J, Ramos M-H, De Roo A (2009) The European flood alert system—part 1: concept and development. Hydrol Earth Syst Sc 13:125-140

UNFCCC COP 21. (2015). Report on COP 21 (FCCC/CP/2015/10/Add.1). In Report of the conference of the parties on its twenty-first session, held in Paris from 30 November to 13 December 2015. Addendum. Part 
two: action taken by the conference of the parties at its twenty-first session (pp. 1-36). Retrieved from http://unfccc.int/resource/docs/2015/cop21/eng/10a01.pdf

United Nations. (2017a). World population prospects 2017 revision (No. ESA/P/WP.250). United Nations population estimates and projections. New York. Retrieved from https://population.un. org/wpp/Publications/Files/WPP2017_Methodology.pdf

United Nations. (2017b). Trends in international migrant stock: the 2017 revision (United Nations database, POP/ $\mathrm{DB} / \mathrm{MIG} / \mathrm{S}$ tock/Rev.2017). New York. Retrieved from http://www. un. org/en/development/desa/population/migration/data/estimates2/docs/MigrationStockDocumentation_2017. pdf

United Nations. (2018). World urbanization prospects: the 2018 revision, Online Edition

Vecchi GA, Soden BJ, Wittenberg AT, Held IM, Leetmaa A, Harrison MJ (2006) Weakening of tropical Pacific atmospheric circulation due to anthropogenic forcing. Nature, 327, 216-219.

Wilby RL, Dessai S (2010) Robust adaptation to climate change. Weather 65(7):180-185. https://doi.org/10.1002 /wea.543

Williams AP, Funk C (2011) A westward extension of the warm pool leads to a westward extension of the Walker circulation, drying eastern Africa. Clim Dyn 37(11-12):2417-2435. https://doi.org/10.1007/s00382-0100984-y

Wu, H., Kimball, J.S., Li, H., Huang, M., Leung, L.R., Adler, R.F., 2012. A new global river network database for macroscale hydrologic modeling. Water Resour Res 48, n/a-n/a. https://doi.org/10.1029/2012WR012313

WWAP (World Water Assessment Programme) (2012) The United Nations world water development report volume 4: managing water under uncertainty and risk. UN water report. UNESCO, Paris. https://doi. org/10.1608/FRJ-3.1.2

Wyser, K., Strandberg, G., Caesar, J., \& Gohar, L. (2017). Documentation of changes in climate variability and extremes simulated by the HELIX AGCMs at the 3 SWLs and comparison in equivalent SST/SIC lowresolution CMIP5 projections, Deliverable 3.1, HEIX. Retrieved from https://www.helixclimate.eu/wpcontent/uploads/2018/04/HELIX-603864-D3.1-Documentation-of-changes-in-climate-variability-andextremes-simulated-by-the-HELIX-AGCMs-copy.pdf

Yamazaki D, O’Loughlin F, Trigg MA, Miller ZF, Pavelsky TM, Bates PD (2014) Development of the Global Width Database for large rivers. Water Resour Res 50:3467-3480. https://doi.org/10.1002/2013WR014664

Publisher's note Springer Nature remains neutral with regard to jurisdictional claims in published maps and institutional affiliations.

\section{Affiliations}

\section{Feyera A. Hirpa ${ }^{1} \cdot$ Lorenzo Alfieri $^{2} \cdot$ Thomas Lees $^{1}$ • Jian Peng ${ }^{1} \cdot$ Ellen Dyer $^{1} \cdot$ Simon J. Dadson $^{1,3}$}

1 School of Geography and Environment, University of Oxford, South Parks Road, Oxford OX1 3QY, UK

2 European Commission, Joint Research Centre (JRC), Ispra, Italy

3 Centre for Ecology and Hydrology, Wallingford, UK 